\title{
POSITION OR PREFERENCE? \\ EXPLAINING PARLIAMENTARY PARTY GROUP LEADERS' ROLE ORIENTATIONS IN BELGIUM
}

\author{
Benjamin de Vet, Ghent University \\ Reviewed version
}

\begin{abstract}
Parliamentary party group leaders (PPG leaders) are understudied but important actors in contemporary parliaments. This article examines the role orientations of PPG leaders in Belgium, using data from 66 semi-structured elite interviews. Contradictory to theoretical views on frontbench roles as institutionally-determined 'position roles' and despite Belgian PPG leaders' comparatively limited intra-party authority, the findings indicate role variation on two dimensions, resulting in five distinct PPG leader role types. These are explained using multi-value Qualitative Comparative Analysis (mvQCA). We find that, while some roles are indeed heavily shaped by contextual factors such as parties' government status, size or electoral performance, others are more clearly driven by individual-level factors such as prior experience or progressive ambitions. As such, this article provides substantial insights into an underexposed aspect of legislative organisation, introduces QCA as a novel method to explain parliamentary roles and makes a theoretical case that also among frontbenchers preference-driven roles are possible.
\end{abstract}

Keywords: Belgium, elite interviews, leaders, parliamentary party groups, parliamentary roles, $Q C A$

Parliamentary party group leaders (PPG leaders) are pivotal players in parliament. They manage parties' legislative branches, co-shape parliamentary agendas, coordinate backbenchers' activities and ensure group unity. As such, they promote political systems' stability, parliaments' decisional efficiency and parties' collective accountability to the electorate (Cox and McCubbins, 1993; Strøm and Müller, 2009). Still, research on PPG leaders is scarce and generally focuses on their part in enforcing party discipline 
(e.g. Bailer, 2017; Kam, 2009). Broader insights into PPG leaders' day-to-day functioning would significantly extend our understanding of legislatures by further opening the 'black box' of group member-leader interactions (Bailer, 2017, p. 13) and shedding light on intra-party decision-making, which typically takes place 'behind closed doors' (Heidar and Koole, 2000).

This article presents an in-depth study of PPG leaders' role orientations and their determinants. Roles reflect individuals' personal view of how someone in their position should appropriately act (Andeweg, 2014). Neo-institutionalists stress that roles result from an interplay between (in)formal norms and individual preferences (Searing, 1994; Strøm, 1997). Simultaneously, however, they classify the roles of frontbenchers as institutionally-predetermined 'position roles' which, unlike backbenchers' 'preference roles', leave little to no room for individual interpretation (Blomgren and Rozenberg, 2012: 21-22; Searing, 1994: 15-16). Consequently, while the literature identified a rich variety of backbench roles, the roles of frontbenchers are generally disregarded. This article advances a less deterministic approach of (PPG) leadership roles. It argues that, due to diverging contextual factors and individuallevel motivations, PPG leaders do adopt different roles by prioritising different dimensions of their jobs, which could have important repercussions on the internal functioning of PPGs and on the behaviour of its members.

We examine role variance within the same institutional setting using a qualitative, single-country study. The focus is on Belgium, where the expected autonomy of PPG leaders in defining their role is low due to the 'partitocratic' nature of policy-making (De Winter and Dumont, 2006) and because of PPG leaders' comparatively weak intra-party position, as intermediates between backbenchers and the powerful central party elite (de Vet and Wauters, 2018). Semi-structured elite interviews (N=66) with current and former PPG leaders in the federal and Flemish parliament and with actors in their direct environments (PPG members, party leaders) provide us with rich data on PPG leaders' self-perceived priorities, goals and motivations, and on other key actors' role expectations. PPG leaders' roles are reconstructed inductively (e.g. Searing, 1994), after which their causal determinants are analysed using multi-value Qualitative Comparative Analysis (mvQCA) (Duşa and Thiem, 2015). 
The findings show that, even in a country where their autonomy is limited, considerable role variance among PPG leaders occurs. Moreover, the explanatory analysis confirms that besides contextual pressures, such as parties' government status, size and short-term electoral performance, also individual factors such as experience and career ambitions explain role choice. As such, this article provides important empirical insights into an underexposed aspect of legislative organisation, and makes an important theoretical case that leadership roles are also driven by preferences. Moreover, by using mvQCA to analyse how roles are shaped by complex interactions of institutional expectations and individual goals, this article is methodologically novel and demonstrates how QCA is highly appropriate for supplementing in-depth descriptive analyses of parliamentary roles with a systematic, variableoriented examination of their determinants.

\section{Parliamentary party group leadership}

PPGs are critical assets of legislative organisation. They reduce transaction costs in legislative bargaining and allow MPs to influence policy through preference aggregation (Heidar and Koole, 2000; Saalfeld and Strøm, 2014). PPGs are typically organised along hierarchical lines. Potentially assisted by whips or vice-chairmen, they are headed by the PPG leader who coordinates MPs' activities and leads discussions on policy positions, communicative strategies and new initiatives' expediency. PPG leaders maintain close contacts with other legislative leaders, co-decide on procedural matters and political agendas, and take the floor when mediatized debates or bills are tabled. Perhaps most importantly, PPG leaders' reputations hinge upon their capacity to maintain unity (Bailer et al., 2009; Laver, 1999). MPs serve multiple principals and might behave in ways that lead to collectively inefficient outcomes (Aldrich, 1995; Kiewiet and McCubbins, 1991). In order to solve the 'collective action problems' that are inherent to the tension between MPs' aim to get re-elected and government by majority rule, parties need leaders that internalize the collective interest, keep tabs on MPs and discourage them from shirking (Bowler et al., 1999; Cox and McCubbins, 1993; Saalfeld and Strøm, 2014).

US Congressional scholars examined whether legislative party leaders influence policy-making (Krehbiel, 1998), if so: how (Cox and McCubbins, 2005) and what conditions strengthen their abilities 
to do so (Aldrich and Rohde, 2000; Strahan, 2011). In Western Europe, where parties' influence in parliament is uncontested, research on PPG leaders is surprisingly scarce and often focuses exclusively on their disciplinary instruments. As ideological agreement or loyalty might not suffice in order to induce the near perfect accounts of party unity recorded in European legislatures (Depauw and Martin, 2009), external pressures might incentivize MPs to toe the party line (Bowler, Farrell and Katz, 1999). While some plead that PPG leaders rarely resort to the employment of sanctions as the perceived threat of their sheer existence might already do the trick (Andeweg and Thomassen, 2011), others argue that PPG leaders do use their 'carrots and sticks', e.g. by granting or depriving speaking time, committee seats or office benefits (Bailer, 2017; Bailer, Schulz and Selb, 2009; Kam, 2009). Many studies moreover take the existence of sanctions as a given and concentrate directly on the moderating effects of institutional variables on unity (e.g. Carey, 2007; Sieberer, 2006).

The focus on their sanctioning capacities has, however, caused scholars to neglect the many other duties PPG leaders fulfil (e.g. coordinating activities, outlining a division of labour). Moreover, rational choice theory, on which many (US Congressional) studies are based, uses simplifying assumptions that generate too parsimonious accounts of political reality. In reality, for instance, PPG leaders might be reluctant to impose sanctions because it might damage their reputation within the party group (Laver, 1999). Moreover, MPs' preferences are not necessarily exogenous to the policy-making process but could be shaped by persuasion, deliberation and new substantial insights (Strahan, 2011). Lastly, PPGs are part of larger party organizations and MPs - including PPG leaders - might be exposed to the desires of extra-parliamentary party actors.

This calls for a broader understanding of PPG leaders' functioning in parliament. How legislators fill in their mandates, and why they do so in a specific way, has traditionally been the focal point of the literature on parliamentary roles.

\section{Roles in parliament}

Legislative roles are 'comprehensive patterns of attitudes and/or behaviour shared by MPs' (Blomgren and Rozenberg, 2012: 8). They allow us to make sense of the regularity of individual behaviour by 
linking politicians to the norms of conduct associated to their institutional position (Andeweg, 2014). Although the study of MPs' roles knows a long-standing research tradition (see: Blomgren and Rozenberg, 2012; Müller and Saalfeld, 1997), it regained attention due to two influential contributions that apply a neo-institutionalist paradigm to the concept.

In his 'motivational approach', Searing (1994) mixes 'rules, roles and reasons' by stating that roles are embedded in institutional contexts, while simultaneously treating role players as purposive actors with a free will: politicians are not locked up in social cages of conformity, nor do they operate within an institutional vacuum. Roles are shaped by (1) formal rules, written down in the organisation's constitutional code, (2) informal norms, i.e. expectations not specified in the formal scheme and (3) individual motivations: career goals and psychological incentives, which are redefined as role players adapt to their environments. Well-known is Searing's distinction between 'position roles' and 'preference roles'. The former refer to leadership positions (e.g. whips) that require the performance of many duties and are therefore almost completely determined by (in)formal norms. The latter are connected to (backbench) positions with fewer responsibilities and allow more individual leeway.

Strøm (1997: 158) sees merit in Searing's insights but contends that 'besides all charming idiosyncrasies, legislators are goal-seeking men or women'. Shifting closer to rational choice theory, he presents a 'strategic approach', conceptualising roles as 'behavioural strategies conditioned by the institutional framework in which parliamentarians operate' (Strøm, 1997: 157). Roles are 'game plans' or 'endogenous prescriptions as to how actors may most successfully and efficiently act to maximize the likelihood of whatever outcomes they favour' (1997: 158). Which role, or strategy, seems fit, is determined by four exogenous, goal-related preferences: reselection, re-election, party office and legislative office. As strategies are repeated day after day, they become routines: systematic patterns of behaviour. A core aspect of these routines is the allocation of one's scarce resources: different goals lead to different strategies and a different allocation of for instance time, media access or voting power.

Both scholars provide valuable analytical frameworks. While Searing advocates thick description and sees (rational and psychological) preferences as endogenous to the role-taking process, Strøm promotes 
parsimony by conceptualising roles as strategic behaviour shaped by exogenous, rational goals. By distinguishing between preference and position roles, however, and by linking frontbenchers to the latter, the neo-institutionalist insights of these frameworks are mostly applied to backbenchers (Blomgren and Rozenberg, 2012: 22). Position and preference roles should be seen as the "polar points on a continuum of institutional constraint' as most real-life roles lie somewhere in between (Strøm, 1997). Also Searing admits that 'even when institutional rules trump individual goals, they cannot fully drive them out of the picture (1994: 200). This theoretical nuance, however, comes less to the forefront in subsequent empirical analyses. While Searing, for instance, subcategorizes multiple backbench roles (e.g. ministerial aspirants, policy advocates, constituency members), his frontbench roles all coincide with their institutionalized position (e.g. 'whips', 'ministers') and preference-driven differences among these actors are only sparsely discussed. As such, the critique that role theorists in the 1960s viewed roles to much as 'group facts' and neglected the individual variety in roles across similar institutional contexts (1994: 25) might also hold for this deterministic interpretation of frontbench roles.

The main theoretical argument driving the distinction between preference and position roles - and between back- and frontbenchers - is related to task differentiation and the importance of one's responsibilities for an organization's functioning. Frontbench roles are more constrained because actors care far more about them. They are linked to well-defined positions to which many responsibilities are assigned and whose proper performance is critical for winning and exercising power effectively (Searing, 1994: 199). This logic can also be found in situational approaches on leadership in organizational psychology, which stress the importance of contextual factors on leadership performance and discretion (Yukl, 2013). Here, however, it is argued that even for people who occupy the highest position within an organizational hierarchy, some scope for role choice remains, exactly because their differentiated responsibilities allow them to (de-)emphasize specific job dimensions (Yukl, 2013; Stewart, 1982). Although leaders indeed face many demands and constraints because of their major responsibilities and many duties, 'the trade-offs inherent among performance dimensions and lack of time to do everything well make it inevitable that different people will define the same job in different ways', which is partly dependent upon leaders' personal interests, skills and values (Yukl, 2013, p. 34). 
This article therefore advances a less deterministic approach on leadership roles. It argues that PPG leaders within the same parliament can conceive of their roles differently exactly because they prioritise specific responsibilities over others. Without developing detailed hypotheses in order to uphold the inductive character of role reconstruction (Searing, 1994), two broader expectations regarding the underlying determinants are formulated. First, diverging informal institutional pressures at the partylevel might lead to different PPG leader roles. For one, parties' government status might play a role. When in government, PPG leaders are not only responsible for ensuring the legislative works' congruence with the party positions but also for ensuring its compliance with coalition compromises (Depauw and Martin, 2009). While majority PPG leaders bear crucial responsibilities in securing cabinet stability (De Winter and Dumont, 2006), opposition PPG leaders might act more independently. Also the size of the PPG might matter: larger PPGs generally face more internally preference heterogeneity and require more elaborate structures and efforts to streamline MPs' activities (Heidar and Koole, 2000; Sieberer, 2006).

Contextual pressures might, however, not always suffice to explain role variance. A second expectation is that also different individual-level goals matter. Like backbenchers, PPG leaders could play 'preference roles'. Particularly career ambitions might be decisive (Strøm, 1997). PPG leadership is often a stepping stone for higher office (party leader, minister) (de Vet and Wauters, 2015). As PPG leaders control resources that can be used for self-promotion (media access, speaking time) (Bailer, 2017), those who aspire higher office might fill in their position differently than a PPG leader approaching his or her political retirement, who is additionally less dependent from the party leadership for their future career.

\section{Data and methodology}

Roles are most accurately studied starting from legislators' own perspectives (Searing, 1994) and taking into account the institutional incentives provided by the characteristic features of a legislature (Blomgren and Rozenberg, 2012; de Vet and Wauters, 2018; Searing, 1994). Therefore, and in order to identify role variance within the same context, this study is designed as a qualitative, single-country case study. 


\subsection{The Belgian case}

The focus is on Belgium, where the position of PPG leader - unlike in other countries - does not coincide with that of party leader (e.g. Westminster democracies, the Netherlands) nor with the presidency of the extra-parliamentary party organization (EPO) (e.g. Spain, Germany) (de Vet and Wauters, 2018). ${ }^{1}$ Instead, Belgian parties' indisputable leaders are the EPO presidents. (S)he has an important say in the selection of PPG leaders who thereafter function as a linking pin between the PPG and the EPO (Pilet \& Wauters, 2014). Due to their comparatively weak intra-party position and because of the general dominance of EPO elites over policy-making in Belgium (De Winter and Dumont, 2006), PPG leaders' leeway in defining their own role is expected to be limited, providing a good case for testing rigid assumptions on frontbench roles. Due to their intermediate positon, PPG leaders may communicate party decisions to MPs and ensure their implementation in parliament. They are, however, also well-placed to inform party elites about issues at stake in the PPG and defend backbenchers' preferences at higher party echelons. This in itself is a topic worth investigating as it might provide MPs, who are generally seen as weak actors in the Belgian 'partitocracy' (De Winter \& Dumont, 2006), an alternative route towards policy influence, outside of the parliamentary arena.

\subsection{Elite interviews and role reconstruction}

We adhere to Searing's motivational approach and use an inductive research design to identify PPG leaders' roles. Unlike Searing, however, who sees roles as 'interrelated goals, attitudes and behaviours' (1994), we more distinctly disentangle the key components (i.e. role attitudes), causes (i.e. expectations, preferences) and consequences (i.e. behaviour) of roles, for reasons of analysis and conceptual clarity (see also: Andeweg, 2014). The focus of this article is mostly on PPG leaders' role attitudes and their causes, less on their behavioural consequences.

The data stem from 66 semi-structured elite interviews that were conducted between May 2017 and 2018 and lasted on average 72 minutes (the shortest took 35 minutes, the longest 3 hours). This resulted

\footnotetext{
${ }^{1}$ In several of these countries, PPG leaders are often the party leader unless the latter moves to the executive.
} 
in over 4700 minutes of tape recordings and 1300 pages of transcript. Most central to this article are the data from 29 interviews with PPG leaders in the federal House of Representatives and Flemish regional parliament. Respondents were selected from all six major Flemish parties and a maximum of heterogeneity within each party based on government status, PPG size and respondents' political experience was pursued (see Table 1 ). ${ }^{2}$ To obtain this within-party variance, we not only interviewed current PPG leaders but also went back to earlier terms. ${ }^{3}$ To enhance the data validity as we deal with recall data in several instances, the interviews were well-prepared by systematically screening media outlets and incorporating questions about actual events during one's term as PPG leader (e.g. intra-party disagreements). Moreover, based on the initial selection of PPG leaders, we additionally selected and interviewed 37 PPG and EPO actors (i.e. MPs, party leaders, senior staff members) in the direct environment of these interviewed PPG leaders. ${ }^{4}$ Although these interviews mainly served to gauge role expectations, they also allowed us to triangulate the findings from the PPG leader interviews, by asking these respondents how specific PPG leaders filled in their position in their view and whether they lived up to the role expectations. ${ }^{5}$

\section{[Table 1]}

Still, as roles are an individuals' personal interpretation of how one should act in a certain position, the descriptive part of the article draws principally on the PPG leader interview data. Although the questionnaires also contained closed-ended questions (e.g. on time allocation), the (inductive) reconstruction of PPG leaders' roles is based on open-ended questions that gauged PPG leaders' self-

\footnotetext{
${ }^{2}$ This purposive 'stratified' sampling strategy aimed at maximal internal heterogeneity makes it more likely that we grasp the full array of PPG leader roles than for instance a random sampling strategy.

${ }^{3}$ Mainly to have majority and opposition PPG leaders in each party (except VB). In practice, we therefore had to go back to the 1999-2003/4 period. A single respondent was PPG leader in the term before that.

${ }^{4}$ Per PPG leader, we interviewed one PPG and one EPO actor. Generally there is overlap and respondents were asked about experiences with multiple PPG leaders.

${ }^{5}$ It should be remarked, however, that no noteworthy discordances could be discerned.
} 
perceived priorities, attitudes, behaviours and their personal preferences, motivations and ambitions (see Appendix 1). ${ }^{6}$ Similar to other studies (Navarro, 2012; Searing, 1994), the transcripts were first coded (with NVivo12) in order to structure the data and delineate patterns or recurrent 'role types' based on PPG leaders' personal priorities and their underlying motivations. In a second phase, we went back to the individual transcripts to match respondents to specific role types.

\subsection{Explanatory analysis using mvQCA}

Methodologically novel is that this article uses (multi-value) QCA to supplement the qualitative reconstruction of roles with an explanatory analysis of their determinants. QCA allows systematic crosscase comparison by converting cases (e.g. PPG leaders) into 'configurations': combinations of explanatory 'conditions' and subsequent 'outcomes' (e.g. role types). It wields a conception of causality ('multiple conjunctural causation') that acknowledges real-world complexity by stating that (1) outcomes are often provoked by a conjunction of conditions rather than a single cause, (2) different combinations of conditions may produce the same outcome and (3) depending on the context, conditions may have a different impact on the outcome. Using its analytical tools based on Boolean algebra, QCA aims to find necessary conditions (which are always present when the outcome occurs) and sufficient conditions (which always lead to certain outcomes) (Rihoux and Ragin, 2009; Schneider and Wagemann, 2012).

Although not often applied to cases at the micro-level, we argue that QCA is highly appropriate for grasping the complex interplay of individual calculations and institutional incentives that underpin legislative roles (rather than focusing on isolable causes). Moreover, by including both contextual and

\footnotetext{
${ }^{6}$ The first broad question immediately taps into what Searing calls 'purposive roles' (1994) as respondents typically answer by telling which responsibilities they prioritise and why they do so. Question 2 and 3 invited respondents to further evaluate their functioning in light of perceived (general and specific) role expectations. Questions 4-6 moved the discussion towards respondents' preferences and ambitions. Although typically already raised at this point, Questions 7 and 8, lastly, further probe into intra-party coordinating tasks (see Appendix 1).
} 
individual-level conditions, we can test neo-institutional approaches' assumptions on leadership roles. Can different institutional constellations alone lead to different role types? Under what circumstances, if any, do individual-level factors play a role? All analyses are performed using $Q C A$ version 3.3 for $R$ (Duşa, 2018).

\section{Research results}

\subsection{A typology of PPG leader roles}

When asked about their priorities, PPG leaders recite a wide array of tasks that go far beyond 'ensuring that everyone pushes the right button during votes' (PPG leader 16). These duties find their origins in informal customs rather than formalized rules and fall into five broader categories. First, PPG leaders are in charge of the group's internal management, which ranges from outlining a division of labour (allocating committees, speaking time), coaching and supervising MPs and staff, to promoting political and interpersonal cohesion and coordinating internal deliberation. Second, as its primary spokesperson, PPG leaders externally communicate the PPGs' positions and policies in parliament and towards the media. Third, PPG leaders liaise between the PPG and the EPO, which means that they can warn party leaders about discontent among MPs, co-shape party policies along backbenchers' wishes but also translate party elite decisions to parliamentary initiatives. Fourth, when in government, PPG leaders additionally liaise with coalition partners (mostly other PPG leaders), defend PPG interests during negotiations and support the majority by defending coalition compromises in the PPG. Fifth, as members of parliaments' governing bodies (e.g. Conference of Group Chairmen), they co-shape the legislative agenda and co-decide over procedural and organizational matters.

Still, notwithstanding these general tasks, almost all interviewed PPG leaders acknowledged that the way they fill in their position probably differs from the way others did. While some attribute this to competence (e.g. eloquence, being a policy generalist), it most of the times reflects a different logic of appropriateness (March and Olsen, 1989) in the heads of respondents, due to diverging contexts or personal incentives. 


\section{[Figure 1]}

In all cases, differences can be distilled to two dimensions that reflect inbuilt dilemmas in the daily activities of PPG leaders. The first distinguishes PPG leaders who primarily adopt an external focus (i.e. seeing themselves as the PPG's figureheads) from those with a distinct internal focus (i.e. PPG leaders as managers). The second relates to PPG leaders' intra-party position and liaising tasks. While some see themselves as representatives of the PPG in EPO decision-making structures, others adopt a more topdown oriented focus aimed at translating party directives in parliament. We identify five PPG leader role types that run along these dimensions, based on respondents' own accounts of their priorities and motivations (Figure 1) ${ }^{7}$

\subsubsection{Party Soldiers}

Party soldiers (12 respondents) prioritise their work behind the scenes and feel it is their duty to ensure that the PPG is a well-organized entity where a collegial atmosphere between MPs is prevalent. They view themselves as 'playmakers' that fairly distribute speaking time and assure that PPG members respect the division of committees and policy areas as allocated at the start of the term. They try to prevent what one respondent called 'border conflicts': common internal tensions that arise when MPs try to 'expand their territory' and intervene in a colleague's area of specialisation. Party soldiers stress their coaching tasks, by transferring political and procedural insights to backbenchers, helping them find the right communicative strategy, building their networks and seeking opportunities for new initiatives. This implies spending a lot of time in parliament and sustaining accessible contacts with PPG members:

It means: being approachable. When MPs call, pick up your phone. Never close your office door. When they have concerns and email you, reply within a few hours. Organize meetings and work things out. Just

\footnotetext{
${ }^{7}$ It should be noted that these are ideal types that squeeze out the idiosyncratic and make diversity intelligible (Searing, 1994: 411). This means that, when looking at the data in closer detail, within each group further diversifications can still be observed.
} 
offer a listening ear and never make them feel as if what they struggle with is unimportant. Because they all have egos, you see (PPG leader 2).

Good PPG leaders, in their view, are empathic, altruistic, know backbenchers' capacities and are able to proactively detect problems within the PPG. Crucially, they do not absorb all public attention but are happy with a more supportive role, even if that implies having to fulfil tasks with low electoral pay-off.

Last week, MP X got a lot of good press on topic $Y$. Not that I am that vain but it was mainly because of a strategy I developed for him. Of course, that is my job and I am glad for him, but what's in it for me? Afterwards I sometimes think: damn, maybe I should try to be in the newspaper a bit more. I would like to get re-elected too, you know (PPG leader 17).

Party soldiers accept their place in the 'back office' mostly because they tend to be seasoned, wellknown politicians that do not need the exposure as much as backbenchers. Through their years of party socialization, they particularly value top-down liaison. It is why many believe they were selected: because of their loyalty ${ }^{8}$, making them a 'safe choice' for party leaders. Many however, nuance that party positions are deliberated upon quite openly in the party executive and that it comes down to transparently briefing decisions to the PPG and setting out the 'pros and cons' of alternatives. Party soldiers' apprehension that top-down liaison is important, stems more from the fact that they often belong to majority parties and see themselves as go-betweens between the executive and parliament. Coalition compromises, implying concessions for all parties, need to be guided through parliament and ideological hardliners have to be convinced. It is not all a one-way street, however. As party soldiers are preoccupied with supporting MPs and understand that proactive involvement is key in policy-making through their experience, they try to assure that MPs can at least express their concerns, for instance by inviting party leaders or ministers to PPG meetings.

\footnotetext{
${ }^{8}$ This party loyalty as a basic characteristic can also be found among backbenchers in what Andeweg (1997) calls the 'partisan role'.
} 


\subsubsection{Parliamentarists}

Similar to the category above, parliamentarists (3 respondents) are foremost preoccupied with the internal PPG management. They state that they spend a lot of time in guiding MPs' activities, get a lot of job satisfaction from delivering sound parliamentary work with the PPG, and do not feel the need to claim all public attention for themselves.

A good PPG leader can coach a group and puts a strong team on the pitch. He is able to communicate the party message, although he should not be the one who always takes centre stage. He should let others score as well. Without it being obvious that he is the one who always gives 'the assist'. A certain degree of discretion. The team above all else (PPG leader 28).

The main difference between party soldiers and parliamentarists is that the latter more distinctly feel that it is their duty to articulate the position of the PPG (or individual MPs) in intra-party meetings and when addressing the wider public. ${ }^{9}$ Two respondents admitted that the fact that they were in opposition probably gave them more opportunities to expound the PPG's positions. The third respondent, belonging to a government party, favoured expressing the PPGs' view because he strongly believed that a degree of dualism between the executive and parliament is desirable:

It is your task to point out to ministers: 'look, we have a PPG, consisting of people with opinions and visions. Communicate with them.' Providing that link is extremely important [...]. Afterwards, you should of course defend government policies but you are also the one that can take it that step further. You should dare to distance yourself a bit from their decisions and give a sharper profile to the PPG by stressing your own demands, without taking it too far. Doing so, is in the interest of the entire party as government policies are coalition compromises (PPG leader 22).

\footnotetext{
${ }^{9}$ They share Searing's (1994) 'parliament men's' respect for the institution and are driven by a similar sense of rectitude and desire to influence policies as his 'policy advocates'.
} 


\subsubsection{Instrumentalists: prodigies and status protectors}

Respondents in the third category tend to see their position as 'instrumental' to achieving their personal goals. In this group, a further distinction is made based on the exact priorities PPG leaders set. Status protectors (5 respondents) are seasoned politicians that do not necessarily have progressive career ambitions but tend to see PPG leadership as a personal power base. They often actively lobbied to be become PPG leader as they 'did not want to be demoted directly to being a normal MP' (PPG leader 10) after being a minister or party president, or because they felt like they were 'wasting away in the backbenches' (PPG leader 23). PPG leadership confirms their status within the party, provides them a public forum and puts them (back) in the party's cockpit. A second subgroup, labelled prodigies (3 respondents), contains young, talented politicians that were selected by the party leadership with the intention of providing them a launching platform. PPG leadership allows them to gain visibility, cope with responsibility and - similar to Searing's (1994) 'ministerial aspirants' - pursue their progressive career ambitions. The specific objectives prodigies and status protectors pursue also affect where exactly on the two dimensions in Figure 1 both subgroups of instrumentalists are situated. While prodigies are primarily focused on getting well-known and raising their personal profile, they can be found near the end of the spearhead-pole of the external/internal dimension. Status protectors, by contrast, are already well-known (and will therefore more rapidly provide opportunities for self-promotion to other MPs) but mostly desire (to keep having) policy influence and focus on the liaising dimension.

\footnotetext{
A basic expectation for a young PPG leader like me was: 'Go forth and multiply.' Become well-known, if possible also popular, get lots of votes in the elections, and - I don't know - maybe become a minister afterwards (PPG leader 1).
}

Instrumentalists have a distinct external focus. In their view, a good PPG leader is a frontrunner and a good debater. They tend to find managerial tasks of secondary importance, stating that it 'requires a lot of your time, but distracts you from the essence: being a spokesperson, preparing debates, going to television appearances, doing parliamentary interventions' (PPG leader 13). They enjoy 'being in the picture' (PPG leader 23) and like that - as opposed to backbenchers - they can intervene in a broad spectrum of topics. While also instrumental for their personal fame and status, they believe that PPG 
leaders (instead of policy specialists) should take the floor when an issue becomes a hot topic in order to give more political weight to the message. This opposes the idea of PPG leaders as playmakers and during the interviews, several accounts have been raised of frustrations among backbenchers, who prepare their cases and build up expertise on detailed policy issues, but do not get to take the floor and generate personal media attention as soon as the issue becomes topical.

Particularly status protectors use their position to influence party policies. They contend that it is their task to promote the views and interests of the PPG in EPO decision-making bodies, although in some cases particularly their own views matter (one PPG leader stated that he was not 'a mail carrier' and that backbenchers should contact the party elite themselves). While prodigies seem more inclined to practice top-down liaison because of their dependence from the party leadership for their future careers, several status protectors state that the party president should personally come to the PPG in order to defend sensitive party decisions:

When the party leader wants to bring a difficult message, he should do it himself. I don't do that, because then I lose my authority. The PPG should be behind me at all times. They should feel as if I am defending their interests. And not have the impression that I am a puppet that pushes through all the decisions party leaders don't want to defend themselves. No, that wouldn't be a good idea (PPG leader 13).

\subsubsection{Crisis managers}

A last group, labelled 'crisis managers', all appear to belong to parties that suffered losses in the foregoing elections which have been the harbinger for internal party renewal. New party presidents with renewed agendas were appointed to turn the electoral tide. They, on their turn, selected relatively unknown politicians as PPG leaders who, together with them, embody the new party image. Consequently, crisis managers stress their loyalty to the new party leadership and prioritise top-down liaison: they support the party leader in his endeavours and try to convince other MPs of the new course the party is heading. This is not always easy as this might invoke opposition among the longer-serving MPs. 
A clear expectation was for me to make the clear change of course as outlined by the party leader. Both in terms of style and policies. Work on a new image, one that people wouldn't directly ascribe to our party. And embody that image. Actively challenge people to address new topics. And remain loyal to the renewed party strategies set out by the new party leader and the people that supported him (PPG leader3).

In order to 'embody the new party message', crisis managers adopt a clear external focus. A good PPG leaders is a good communicator who does not act primarily out of self-interest but convincingly tries to translate party policies to a broader audience. More than instrumentalists, however, crisis managers are preoccupied with the internal management of the PPG. They face greater disunity and state that they put a lot of effort in convincing PPG members and avoiding that dissidence reaches the outside world, given the already precarious situation the party finds itself in.

\subsection{Position or preference? Explaining roles using $m v Q C A$}

\subsubsection{Operationalisation and truth tables}

The first step in QCA's analytical procedure ${ }^{10}$ consists of operationalising the truth tables, which link cases (i.e. PPG leaders) to configurations of conditions and outcomes (Schneider and Wagemann, 2012: 91). We use multi-value QCA (Duşa and Thiem, 2015) as the outcomes are operationalised into five mutually-exclusive categories that indicate respondents' roles: either party soldier (PS), crisis manager (CM), parliamentarist (PA), status protector (SP) or prodigy (PR). The conditions are all operationalised in binary terms. They are selected based on the theoretical expectations expressed above and because of their empirical relevance as pointed out during the interviews. In a first step, we only integrate partylevel conditions to examine to what degree contextual pressures alone explain PPG leaders' roles. Four party-level factors stand out as key informal institutional constraints shaping the roles of PPG leaders. The first is cases' government status (GOV), which is dichotomised into either ' 1 ' (majority) or ' 0 ' (opposition). While majority parties need leaders that focus on top-down liaison and on the PPGs'

\footnotetext{
${ }^{10}$ For a hands-on and accessible text on QCA's application see Schneider \& Wagemann (2012). For technical guidelines on how to use the QCA-package in R, see Duşa (2018).
} 
internal management, opposition PPG leaders seem to enjoy more leeway to take up positions at the other end of the dimensions in Figure 1. Second, the size of the PPG also affects the need for internal coordination among MPs. Large PPGs (LP) (1) more distinctly seem to require an internally-focused PPG leader and are distinguished from small PPGs (0) using 15 seats - the mean PPG size for all selected parties in the House since 1995 (i.e. the population mean) - as a threshold. ${ }^{11}$ For the third condition, indicating if PPG leaders are 'central party appointees' (CPA), we asked PPG and EPO actors to indicate on 10-point scales how much in their view, a number of actors weighed on the choice to select person $X$ as PPG leader. When EPO actors score highest, PPG leaders are labelled ' 1 '; if the PPG was decisive, ' 0 '. ${ }^{12}$ It is expected that PPG leaders who were selected by the PPG are more inclined to conduct bottomup liaison than those selected by the EPO leadership. A fourth condition is selected mostly because of its obvious empirical relevance mostly for the role of crisis manager. It indicates whether a party made relative electoral gains (EG) in the previous (federal or regional) election $t$ (1) compared to election $t-1$ or if it suffered relative losses (0).

[Table 2]

In Table 2, we see that the first truth table has some explanatory power. This is demonstrated by the first row where the presence of the same conditions drive five cases to the party soldier role. However, 6 out of 12 rows are 'contradictory configurations': rows where the same combination of conditions lead to different outcomes. Row 3, for one, applies to three PPG leaders with the same contextual background. While PPG leader 2 and 5 are internally-oriented party soldiers, PPG leader 1 is an externally-oriented prodigy. Our strategy for resolving contradictory rows is adding an extra condition (Schneider and Wagemann, 2012: 120-123). We include the individual-level condition 'political experience' (EXP).

\footnotetext{
${ }^{11}$ Taking the mean PPG size in the federal and Flemish parliament (17 seats) since 1995 does alter the results since the dataset contains no PPGs of 15 or 16 seats.

${ }^{12}$ We obtained the judgement of two respondents (one PPG and one EPO actor) per PPG leader. In case of contradictory judgements (one case), we turned towards PPG leaders' own assessment.
} 
The interviews made clear that experience has an important influence on the roles of PPG leaders as it is related to prior socialization but mostly to (the pursuit or fulfilment of) career ambitions (see also: Strøm, 1997). While young, inexperienced PPG leaders seem more inclined to adopt an externallyoriented role with the main purpose of building their personal reputation, more experienced, well-known PPG leaders have less to prove and often already fulfilled their ambitions (e.g. as former minister), making them more willing to adopt a back-office, internally-oriented position. As for the operationalisation, we look at respondents experience (EXP) as a member of (regional and federal) parliament and/or government. Population data reveals that PPG leaders' prior parliamentary experience is on average two legislative terms (de Vet and Wauters, 2015). Respondents who became PPG leader in their first or second term are labelled 'inexperienced' (0); the others, or those who served as minister before, are labelled 'experienced' (1).

\section{[Table 3]}

In Table 3, the number of contradictory rows drops from 6 to 3 (i.e. 7 instead of 16 cases). Remaining inconsistencies can be explained by returning to the interview data. Row 2 contains two crisis managers (case 4 and 24) who were both appointed to help turn the party's electoral tide. PPG leader 23, a status protector, in fact actively lobbied to replace PPG leader 24 by the end of that same legislative term, when the party's electoral prospects started to look brighter, and did so mainly in order to get back in the picture: 'my entire career, I was in the forefront and all of a sudden I sat there in the back of parliament. Once I got the opportunity to return, I didn't hesitate too long" (PPG leader 24). Also in the other two contradictory rows it seems a matter of ambition. PPG leader 21 (a parliamentarist) too sees differences between himself and PPG leader 20, a prodigy: "he is more temperamental: politics runs through his veins. When something starts to smoke, he wants to jump straight on it himself'. That's not how I would act”. Differences between PPG leader 19 (a parliamentarist) and 27 (a status protector) stem from the fact that the former more actively tried to give a platform to the PPGs' youngsters as he knew that he would retire before the next election, while the latter saw his mandate as a way to generate personal public attention. As experience as a condition does reduce many contradictory configurations, because it is generally, but not always, linked to ambition, we proceed with this table. 


\subsubsection{Analysis of necessity}

Necessary conditions are conditions that are always present when an outcome is present. They are found for each role type. The coverage measure indicates their relevance: values approaching 1 indicate high relevance, low values indicate trivialness (see: Schneider and Wagemann, 2012: 144-147).

Party soldiers are always in government. The coverage value is high (0.8) and indicates that $80 \%$ of the majority PPG leaders in the dataset belong to this role type. Exceptions are PPG leader 1, an ambitious prodigy, and a somewhat surprising choice as a PPG leader for a large majority party, PPG leader 22, a parliamentarist, convinced that a degree of dualism between the executive and parliament is desirable, and PPG leader 27, a status protector with a lot of weight in the party. Interestingly, for the second role type three conditions are necessary: crisis managers always belong to opposition parties that suffered electoral losses and were always appointed by the central party elite. The coverage of these conjugated conditions is high (0.75). The cases where the presence of these conditions does not lead to the outcome are two 'status protectors' that in fact succeeded (PPG leader 24; see above) or briefly preceded (PPG leader 10) a 'crisis manager' in the same legislative term. For the other three role types experience (status protector) or the absence thereof (prodigy and parliamentarist) is a necessary condition. The coverages are, however, low (respectively $0.33 ; 0.21$ and 0.21 ), indicating that many respondents with the same condition values fall into other roles.

These results to some degree already indicate that the roles of party soldier and crisis manager are two (albeit inherently different) 'position roles': contextual conditions are crucial for the presence of these roles as outcomes. The other roles could be seen as 'preference roles' since they are always linked to individual-level conditions. Still, the lower coverage values indicate that also here the context must allow for the expression of these roles. In order to fully explain roles' occurrence, we turn towards the analysis of sufficiency.

\subsubsection{Analysis of sufficiency}

Conditions are sufficient if the outcome always occurs when they are present (Rihoux and Ragin, 2009). The analysis of sufficiency is based on the 'truth table algorithm', which translates truth table rows into 
Boolean expressions and 'minimizes' them into more parsimonious formulas by removing logically redundant conditions (see: Schneider and Wagemann, 2012: 178-193). We do not incorporate logical remainders and only report the conservative solution formula (Schneider and Wagemann, 2012: 162). ${ }^{13}$ The consistency parameter indicates to what degree the statement of sufficiency is backed by empirical evidence (i.e. it shows whether formulas apply to contradictory cases). Raw coverage indicates how much of the outcome is explained by a single path; unique coverage how much it uniquely covers (see: Schneider and Wagemann, 2012: 129-139).

\section{[Table 4]}

Table 4 shows that several solution formulas provide clear paths towards certain roles. Constant in the four expressions for party soldiers is the prevalence of belonging to a government party but also leading a large PPG and having a lot of political experience are important factors. The directional impact of being a central party appointee or parties' result the previous elections are less unequivocal. Crisis managers probably constitute the best explained role type: they are central party appointees that belong to opposition parties which suffered electoral losses, and they either lead a relatively small PPG or have little experience, which coincides with the idea of launching 'new faces'.

The three other roles portray more diverse explanatory paths with greater influence of individual-level factors. For parliamentarists, only not having too much experience is constant (although it is not hard to imagine an experienced parliamentarist). All other conditions have varying effects. The same applies to prodigies. For status protectors, only having a lot of experience is constant; whether you lead a large party, were selected by the EPO or if the party won in the recent elections has a less unequivocal impact. It should be noted that the coverage values indicate that most (but not all) PPG leaders in the last three role types belong to opposition parties.

\footnotetext{
${ }^{13}$ We do incorporate contradictory rows as they at least make the outcome possible (Schneider \& Wagemann, 2012: 12).
} 
In sum, the analyses show that multiple configurations lead to different PPG leader roles, and that both diverging contextual and individual factors matter. In some cases, roles appear 'position roles' as their explanatory paths are quite coherently determined by the presence of institutional pressures (i.e. party soldiers and crisis managers). In others they appear 'preference roles' as the (contextual) explanatory paths are less conclusive, leaving more room for individual-level factors.

\section{Conclusion}

This article examined the roles of PPG leaders as important but understudied actors in parliamentary democracies. Based on elite interview data, we showed how PPG leaders in Belgium fill in their position differently and what factors explain their role orientations. The findings, which provide substantive insights into an underexposed aspect of legislative organisation, have both theoretical and methodological implications for parliamentary role research.

First, this article demonstrates how mvQCA can be used to study MPs' roles. By examining how explanatory variables conjugate, QCA is designed for grasping causal complexity (Schneider and Wagemann, 2012) and provides an appropriate methodological tool for analysing the complex interactions between institutional pressures and individual goals that underpin legislative roles. QCA allows scholars to combine in-depth insights into roles (e.g. based on interview data) with a transparent and systematic analysis of their determinants. As such, it provides a middle ground between (qualitative) case-oriented and (quantitative) variable-oriented approaches on roles (Blomgren and Rozenberg, 2012).

Secondly, this article makes a theoretical case that frontbenchers do not only play institutionallypredetermined 'position roles'. Even in Belgium, where their (intra-party) authority is limited, PPG leaders within the same institutional context do prioritise different aspects of their jobs and do conceive of their roles differently. Indeed, diverging contextual factors (but at the party-level) such as a PPG's size but particularly parties' government status ('party soldiers') and recent electoral losses ('crisis managers') do serve as institutional constraints influencing PPG leaders' role choice. These factors alone can, however, only partially explain role variance as also individual preferences matter. While some 
roles (i.e. party soldiers; crisis managers) are indeed clearly associated with institutional expectations, others (i.e. parliamentarists, status protectors and prodigies) are so less conclusively and are more satisfactorily explained by taking individual motivations into account. As such, even when frontbench roles in parliament are indeed more institutionally constrained than the roles of backbenchers, they are not 'position roles' by default as also here 'preference roles' are possible.

The latter should encourage scholars to extend their focus from only studying the roles of backbenchers to also examining those of frontbenchers, particularly given the latter's impact on legislative decisionmaking. Although roles are context-specific (Blomgren and Rozenberg, 2012; de Vet and Wauters, 2018), the two broader dimensions that structure PPG role variance in Belgium are rather likely to recur in other countries. Differences on the internal-external dimension appear related rather universal parliamentary incentives like political ambition and can, for instance, be linked to the upcoming literature on personalised parliamentary behaviour (e.g. Louwerse and Otjes, 2016), investigating whether legislators (progressively) adopt individualistic goal-seeking behaviour. Additionally, the liaising dimension - which taps into conceptualizations of legislators as agents with multiple, potentially adversarial principals (e.g. Carey, 2007) - might also matter in countries where PPG leaders normally have a more prominent intra-party position (e.g. The Netherlands, Germany) but when the (parliamentary) party leader moves to government and is replaced as by someone who plays an important part as a go-between between the PPG and the party-in-government.

This study also raises new questions. Future studies could examine the roles of PPG leaders in different political settings and further disentangle the causes of diverging PPG leader roles. Moreover, as this article was mostly concerned with roles as dependent variables, research should investigate the consequences of PPG leaders' role orientations. How and to what extent are different role orientations translated into characteristic behaviour? What are the implications of PPG leaders' different role orientations for PPGs' internal organisation and the behaviour of its members? 


\section{References}

Aldrich, J.H. (1995) Why parties? The origin and transformation of political parties in America, University of Chicago Press: Chicago.

Aldrich, J.H. and Rohde, D.W. (2000) The logic of conditional party government: Revisiting the electoral connection, PIPC: Durham.

Andeweg, R. (2014) 'Roles in legislatures', in Martin, S., Saalfeld, T. and Strøm, K. (eds.), The Oxford handbook of legislative studies: Oxford University Press.

Andeweg, R.B. (1997) 'Role specialisation or role switching? Dutch MPs between electorate and executive', The Journal of Legislative Studies 3, 110-27.

Andeweg, R.B. and Thomassen, J. (2011) 'Pathways to party unity: Sanctions, loyalty, homogeneity and division of labour in the Dutch parliament', Party Politics 17, 655-72.

Bailer, S. (2017) 'To use the whip or not: Whether and when party group leaders use disciplinary measures to achieve voting unity', International Political Science Review 39, 163-77.

Bailer, S., Schulz, T. and Selb, P. (2009) 'What role for the party group leader? A latent variable approach to leadership effects on party group cohesion in the European Parliament', The Journal of Legislative Studies 15, 355-78.

Blomgren, M. and Rozenberg, O. (eds.) (2012) Parliamentary roles in modern legislatures, Routledge: Oxon.

Bowler, S., Farrell, D.M. and Katz, R.S. (1999) Party discipline and parliamentary government, Ohio State University Press: Columbus.

Carey, J.M. (2007) 'Competing principals, political institutions, and party unity in legislative voting', American Journal of Political Science 51, 92-107.

Cox, G.W. and McCubbins, M.D. (1993) Legislative leviathan: Party government in the House, University of California Press: Berkeley.

Cox, G.W. and McCubbins, M.D. (2005) Setting the agenda: Responsible party government in the US House of Representatives, Cambridge University Press: Cambridge.

de Vet, B. and Wauters, B. (2015) 'Tussen partij en parlement: het profiel van de fractievoorzitter in België', RES PUBLICA 57, 185-215.

de Vet, B. and Wauters, B. (2018) 'Follow the leader: testing a deductive approach for studying parliamentary party leadership roles', The Journal of Legislative Studies 24, 359-72.

De Winter, L. and Dumont, P. (2006) 'Do Belgian Parties Undermine the Democratic Chain of Delegation?', West European Politics 29, 957-76.

Depauw, S. and Martin, S. (2009) 'Legislative party discipline and cohesion in comparative perspective', in Giannetti, D. and Laver, M. (eds.), Intra-party politics and coalition governments: Routledge: 103-20.

Duşa, A. (2018) QCA with R: A Comprehensive Resource, Springer: New York.

Duşa, A. and Thiem, A. (2015) 'Enhancing the Minimization of Boolean and Multivalue Output Functions With e QMC', The Journal of Mathematical Sociology 39, 92-108.

Heidar, K. and Koole, R. (eds.) (2000) Parliamentary party groups in European democracies: political parties behind closed doors, Routledge: London.

Kam, C.J. (2009) Party discipline and parliamentary politics, Cambridge University Press: Cambridge.

Kiewiet, D.R. and McCubbins, M.D. (1991) The logic of delegation, University of Chicago Press: Chicago.

Krehbiel, K. (1998) Pivotal Politics: A Theory of US Lawmaking, University of Chicago Press: Chicago.

Laver, M. (1999) 'Divided parties, divided government', Legislative Studies Quarterly 24, 5-29.

Louwerse, T. and Otjes, S. (2016) 'Personalised parliamentary behaviour without electoral incentives: the case of the Netherlands', West European Politics 39, 778-99.

March, J.G. and Olsen, J.P. (1989) Rediscovering Institutions: The Organizational Basis of Politics, Free Press:New York.

Müller, W.C. and Saalfeld, T. (eds.) (1997) Members of Parliament in Western Europe: roles and behaviour, Frank Cass: London. 
Navarro, J. (2012) 'The cognitive rationality of role choices. Evidence from the European Parliament', in Blomgren, M. and Rozenberg, O. (eds.), Parliamentary roles in modern legislatures: Routledge: $185-210$.

Rihoux, B. and Ragin, C.C. (2009) Configurational Comparative Methods. Qualitative Comparative Analysis and Related Techniques, Sage: London.

Saalfeld, T. and Strøm, K. (2014) 'Political parties and legislators', in Martin, S., Saalfeld, T. and Strøm, K. (eds.), The Oxford handbook of legislative studies: Oxford University Press.

Schneider, C.Q. and Wagemann, C. (2012) Set-theoretic methods for the social sciences: A guide to qualitative comparative analysis, Cambridge University Press: Cambridge.

Searing, D. (1994) Westminster's world: understanding political roles, Cambridge University Press: Cambridge.

Sieberer, U. (2006) 'Party unity in parliamentary democracies: A comparative analysis', The Journal of Legislative Studies 12, 150-78.

Strahan, R. (2011) 'Party leadership', in Edwards, G., Lee, F. and Schickler, E. (eds.), The Oxford Handbook of the American Congress: Oxford University Press: 371-95.

Strøm, K. (1997) 'Rules, reasons and routines: Legislative roles in parliamentary democracies', in Müller, W.C. and Saalfeld, T. (eds.), Members of Parliament in Western Europe. Roles and Behavior: Frank Cass: 155-74.

Strøm, K. and Müller, W.C. (2009) 'Parliamentary Democracy, Agency Problems and Party Politics', in Giannetti, D. and Benoit, K. (eds.), Intra-party politics and coalition governments: Routledge: $25-50$.

Yukl, G.A. (2013) Leadership in organizations, Pearson: Boston.

\section{Appendix 1: open-ended interview questions}

1. PPG leaders perform a multitude of duties, both within and outside of parliament. Thinking about your term as a PPG leader, what do/did you personally see as your three most important responsibilities?

Probes: Are these also the activities that required most of your time? Were there any tasks which you find/found less important? Which tasks did you typically delegate to your personal staff(e.g. the PPG secretary)?

2. What, in your personal view, constitutes a good PPG leader?

Probes: Do you see differences in terms of how PPG leaders, both from your own and other parties, fill in their position? In what ways? Why do you believe this is the case?

3. Why do you think you were initially selected as a PPG leader [on moment T]?

Probes: Were there any other candidates? Why do you think they weren't selected? Who made the final call? Did they specify concrete expectations towards your future functioning? 
4. Why did you initially want to become PPG leader yourself?

5. Which intrinsic aspect of your job as a PPG leader do/did you find most satisfying?

Probes: Why is that? Which aspects do/did you find least satisfying? Why?

6. PPG leaders sometimes proceed to other political positions like party leader, minister or Speaker after their terms. Did/do you personally have the ambition to take up such an ambition afterwards? [+ own collected information on respondents' careers].

Probes: Which position? Why?

7. Within political parties, differences of opinions occasionally arise. On which concrete policies or occasions were the party elite and (specific) PPG members not on the same wavelength? [+ own examples from media outlets].

Probes: How should a PPG leader act in such a situation? How did you personally act in [case X]? Why?

8. Majority PPG leaders often find themselves in a position in which they both have to guarantee the PPG's loyalty to the cabinet, whilst also making sure that the PPG can sufficiently raise its own profile. How did you personally try to cope with this 'field of tension'?

Probes: Do you think other PPG leaders cope with this field of tension differently? Were there specific instances where you had to temper the diligence or wishes of backbenchers? Were there instances where you gave more leeway to PPG members? 
Table 1. Overview of interviewed PPG leaders' characteristics

\begin{tabular}{lccccccc}
\hline & & \multicolumn{2}{c}{ Government status } & \multicolumn{2}{c}{ Political experience* } & \multicolumn{2}{c}{ PPG size (seats) } \\
Party & $N$ & Majority & Opposition & Inexperienced & Experienced & $\begin{array}{c}\text { Small } \\
(<15)\end{array}$ & $\begin{array}{c}\text { Large } \\
(\geq 15)\end{array}$ \\
\hline Liberals (VLD) & 5 & 4 & 1 & 2 & 3 & 1 & 4 \\
Socialists (SPA) & 5 & 3 & 2 & 2 & 3 & 1 & 4 \\
Ecologists (Groen) & 5 & 2 & 3 & 3 & 2 & 4 & 1 \\
Christian dem. (CD\&V) & 5 & 2 & 3 & 2 & 3 & 0 & 5 \\
Regionalists (NVA) & 5 & 4 & 1 & 3 & 2 & 3 & 2 \\
Radical right (VB) & 4 & 0 & 4 & 2 & 2 & 3 & 1 \\
Total & 29 & 15 & 14 & 14 & 15 & 12 & 17
\end{tabular}

*Population data reveals that PPG leaders' prior experience is on average 2 legislative terms (de Vet \& Wauters, 2015).

Respondents who became PPG leader in their first or second term are labelled as 'inexperienced'. The others (or those with ministerial experience) as 'experienced'. 
Figure 1. PPG leader role types in Belgium

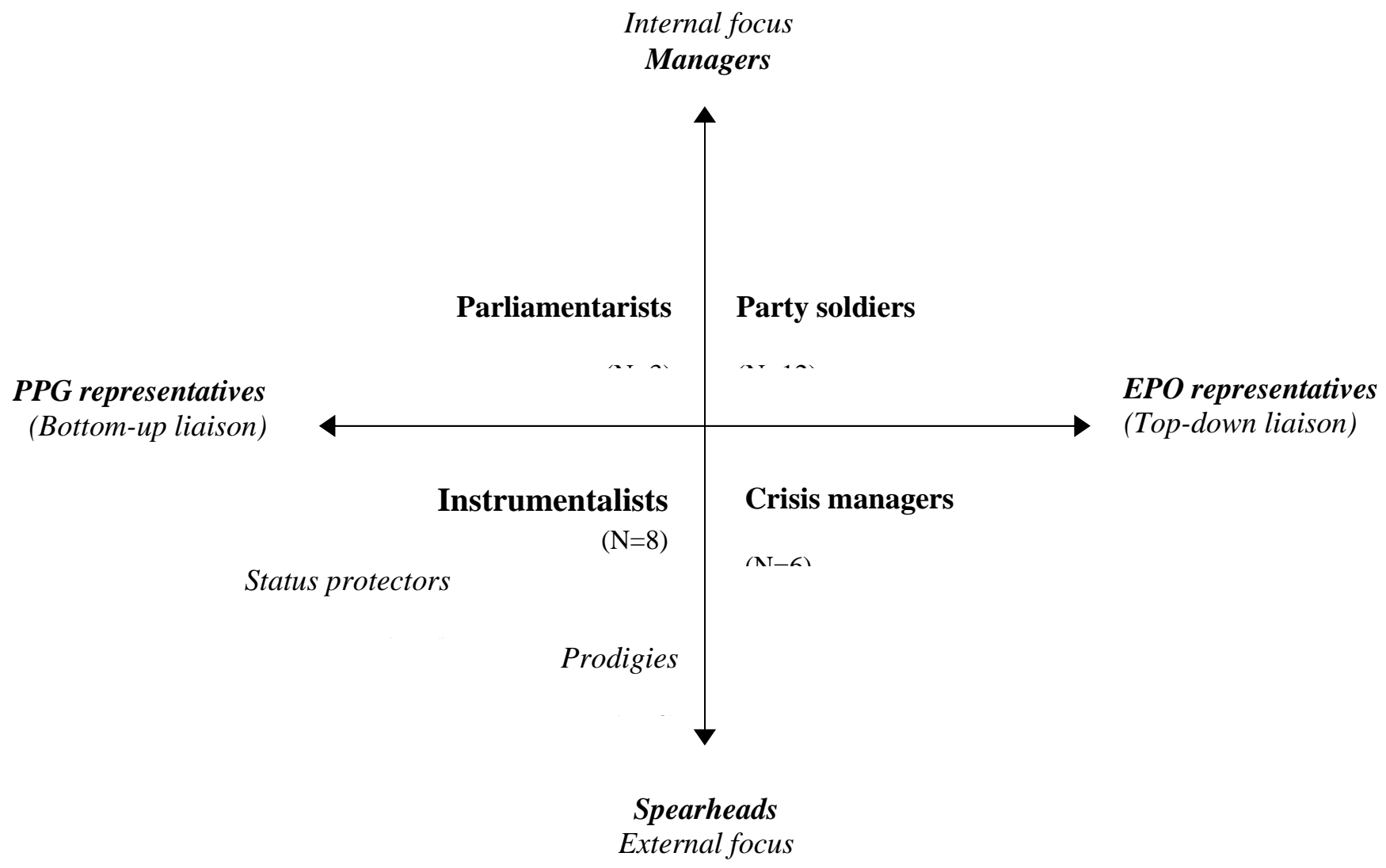


Table 2. QCA Truth table with only institutional (party-level) conditions

\begin{tabular}{ccccccc}
\hline & \multicolumn{9}{c}{ Conditions } & & Cases \\
\cline { 2 - 5 } Row & GOV & LP & EG & CPA & Outcome & $16,17,25,26,29$ \\
1 & 1 & 1 & 1 & 1 & PS & $4,11,14,23,24$ \\
2 & 0 & 0 & 0 & 1 & CM/SP & $1,2,5$ \\
3 & 1 & 1 & 0 & 1 & PS/PR & $12,20,21$ \\
4 & 0 & 0 & 1 & 0 & SP/PR/PA & $3,8,10$ \\
5 & 0 & 1 & 0 & 1 & CM/SP & 19,27 \\
6 & 1 & 0 & 1 & 0 & PS/SP & 18,22 \\
7 & 1 & 0 & 1 & 1 & PS/PA & 6,7 \\
8 & 1 & 1 & 0 & 0 & PS & 9 \\
9 & 1 & 1 & 1 & 0 & PS & 15 \\
10 & 0 & 0 & 1 & 1 & PR & 28 \\
11 & 0 & 1 & 0 & 0 & PA & 13 \\
12 & 0 & 1 & 1 & 0 & SP & \\
\hline
\end{tabular}

Note: GOV = government party; LP = large PPG; EG = electoral gain; CPA = central party appointee; PS= Party Soldier; $\mathrm{CM}=$ Crisis Manager; $\mathrm{SP}=$ Status Protector; $\mathrm{PR}=$ Prodigy $; \mathrm{PA}=$ Parliamentarist . 
Table 3. QCA Truth table including 'experience' as a condition

\begin{tabular}{cccccccc}
\hline & \multicolumn{5}{c}{ Conditions } & & \\
Row & GOV & LP & EG & CPA & EXP & Outcome & Cases \\
\hline 1 & 1 & 1 & 1 & 1 & 0 & PS & $16,17,29$ \\
2 & 0 & 0 & 0 & 1 & 1 & CM/SP & $4,23,24$ \\
3 & 1 & 0 & 1 & 0 & 1 & PS/SP & 19,27 \\
4 & 1 & 1 & 0 & 1 & 1 & PS & 2,5 \\
5 & 1 & 1 & 1 & 1 & 1 & PS & 25,26 \\
6 & 0 & 0 & 0 & 1 & 0 & CM & 11,14 \\
7 & 0 & 0 & 1 & 0 & 0 & PA/PR & 20,21 \\
8 & 0 & 1 & 0 & 1 & 0 & CM & 3,8 \\
9 & 1 & 0 & 1 & 1 & 1 & PS & 18 \\
10 & 1 & 1 & 0 & 0 & 0 & PS & 6 \\
11 & 1 & 1 & 0 & 0 & 1 & PS & 7 \\
12 & 1 & 1 & 1 & 0 & 1 & PS & 9 \\
13 & 0 & 0 & 1 & 0 & 1 & SP & 12 \\
14 & 0 & 0 & 1 & 1 & 0 & PR & 15 \\
15 & 0 & 1 & 0 & 0 & 0 & PA & 28 \\
16 & 0 & 1 & 0 & 1 & 1 & SP & 10 \\
17 & 0 & 1 & 1 & 0 & 1 & SP & 13 \\
18 & 1 & 0 & 1 & 1 & 0 & PA & 22 \\
19 & 1 & 1 & 0 & 1 & 0 & PR & 1 \\
\hline
\end{tabular}

Note: $\mathrm{GOV}=$ government party; $\mathrm{LP}=$ large $\mathrm{PPG} ; \mathrm{EG}=$ electoral gain; $\mathrm{CPA}=$ central party appointee; $\mathrm{PS}=$ Party Soldier; $\mathrm{CM}=$ Crisis Manager; $\mathrm{SP}=$ Status Protector; $\mathrm{PR}=$ Prodigy; $\mathrm{PA}=$ Parliamentarist. 
Table 4. Analysis of sufficiency: conservative solution formulas

\begin{tabular}{|c|c|c|c|c|c|}
\hline \multirow[b]{2}{*}{ Outcome } & \multirow[b]{2}{*}{ Solution } & \multirow[b]{2}{*}{ Consistency } & \multicolumn{2}{|c|}{ Coverage } & \multirow[b]{2}{*}{ Cases } \\
\hline & & & Raw & Unique & \\
\hline \multirow{5}{*}{$\begin{array}{r}\text { Party Soldier } \\
(P S)\end{array}$} & GOV*LP*EXP & 1.000 & 0.500 & 0.167 & $7 ; 2,5 ; 9 ; 25,26$ \\
\hline & $\mathrm{GOV}^{*} \mathrm{EG}^{*} \mathrm{EXP}$ & 0.833 & 0.417 & 0.167 & 19,$27 ; 18 ; 9 ; 25,26$ \\
\hline & $\mathrm{GOV}^{*} \mathrm{LP}^{*}$ eg*cpa & 1.000 & 0.167 & 0.083 & $6 ; 7$ \\
\hline & GOV*LP*EG*CPA & 1.000 & 0.417 & 0.250 & $16,17,29 ; 25,26$ \\
\hline & Total & 0.923 & 1.000 & & \\
\hline \multirow{3}{*}{$\begin{array}{r}\text { Crisis Manager } \\
(C M)\end{array}$} & gov*lp*eg*CPA & 0.800 & 0.667 & 0.333 & 11,$14 ; 4,23,24$ \\
\hline & gov*eg*CPA*exp & 1.000 & 0.667 & 0.333 & 11,$14 ; 3,8$ \\
\hline & Total & 0.857 & 1.000 & & \\
\hline \multirow{4}{*}{$\begin{array}{r}\text { Parliamentarist } \\
(P A)\end{array}$} & gov*lp*EG*cpa*exp & 0.500 & 0.333 & 0.333 & 20,21 \\
\hline & GOV*lp*EG*CPA*exp & 1.000 & 0.333 & 0.333 & 22 \\
\hline & gov*LP*eg*cpa*exp & 1.000 & 0.333 & 0.333 & 28 \\
\hline & Total & 0.750 & 1.000 & & \\
\hline Prodigy & gov*lp*EG*exp & 0.667 & 0.667 & 0.667 & 20,$21 ; 15$ \\
\hline \multirow{2}{*}{$(P R)$} & GOV*LP*eg*CPA*exp & 1.000 & 0.333 & 0.333 & 1 \\
\hline & Total & 0.750 & 1.000 & 1.000 & \\
\hline \multirow{4}{*}{$\begin{array}{r}\text { Status Protector } \\
(S P)\end{array}$} & gov*EG*cpa*EXP & 1.000 & 0.400 & 0.200 & $12 ; 13$ \\
\hline & gov*eg*CPA*EXP & 0.500 & 0.400 & 0.400 & $4,23,24 ; 10$ \\
\hline & $1 \mathrm{p} * \mathrm{EG}^{*} \mathrm{cpa}^{*} \mathrm{EXP}$ & 0.667 & 0.400 & 0.200 & $12 ; 19,27$ \\
\hline & Total & 0.625 & 1.000 & & \\
\hline
\end{tabular}

Note: Uppercases denote the presence of a condition, lowercases the absence. * indicates the conjunction of conditions. $\mathrm{GOV}=$ government party; $\mathrm{LP}=$ large $\mathrm{PPG} ; \mathrm{EG}=$ electoral gain; $\mathrm{CPA}=$ central party appointee; $\mathrm{EXP}=$ experienced. 